\title{
DEPÓSITOS EÓLICOS INATIVOS DO SUB-MÉDIO SÃO FRANCISCO, EVIDÊNCIAS DE ATIVI- DADE EÓLICA DURANTE O PLEISTOCENO, PERNAMBUCO, NORDESTE DO BRASIL
}

\section{Eolian Inactive deposits of the Sub-Middle San Francisco, Pernambuco, Northeastern Brazil, eolian activity during the Pleistocene}

\author{
Bruno Ferreira \\ Doutorando em Geociências, Universidade Federal de Pernambuco - UFPE \\ brunge2005@gmail.com \\ Antônio Carlos de Barros Correa \\ Prof. Dr. UFPE. Bolsista Cnpq. \\ dbiase2001@terra.com.br \\ Alcina Magnólia Franca Barreto \\ Profa. Dra. UFPE. Bolsista Cnpq. \\ alcina@ufpe.br
}

Artigo recebido em 30/06/2012 e aprovado para publicação em 08/08/2012

Resumo: $\quad$ Esse estudo teve como objetivo compreender a dinâmica de evolução geológica recente do vale do Rio São Francisco, no Estado de Pernambuco. A metodologia utilizada compreende dois tipos de análises: uma geomorfológica a partir da realização de mapeamento de detalhe, identificando uma unidade morfoestrutural e suas respectivas morfoesculturas, a outra geocronológica, com idades obtidas por Luminescência Opticamente Estimulada. Os resultados mostram dois conjuntos morfoesculturais eólicos elaborados ao longo do Pleistoceno tardio, com atividade deposicional até a transição para o Holoceno. A metodologia utilizada se mostrou bastante satisfatória, contudo a região ainda muito é carente de dados paleoambientais.

Palavras chave: Geomorfologia; Geocronologia; Rio São Francisco; Nordeste do Brasil.

\begin{abstract}
This study aimed at understanding the dynamics of the recent geologic evolution in the São Francisco river valley, State of Pernambuco. The applied methodology encompasses two types of analysis, a geomorphologic one based on the elaboration of a detailed map, identifying a morphostructural unit and their respective morphosculptures. The second analysis was a geochronologic one based on Optically Stimulated Luminescence. The results pointed to the existence of two sets of eolian morphosculptures shaped along the late Pleistocene, exhibiting depositional activity until the Holocene transition. The applied methodology proved quite satisfactory in this region which is still lacking paleoenvironmental data.

Keywords: Geomorphology; Geochronology; São Francisco river; Northeast of Brazil.
\end{abstract}




\section{INTRODUÇÃO}

Compreender a dinâmica da natureza, enquanto formadora da paisagem, através dos seus processos físico-químicos-biológicos naturais, constitui o objeto de interesse das geociências. As formas de relevo, alvo dos estudos geomorfológicos, são resultantes de processos que atuaram, com intensidades variadas, no passado e no presente. Sua interpretação genética busca compreender a origem das formas concebidas e reafeiçoadas em um passado geológico recente (CORRÊA, 2001; FERREIRA, 2010).

Segundo Suguio (2005) ao longo do Quaternário as paisagens tropicais brasileiras passaram por sensíveis mudanças em decorrência das variações da circulação atmosférica regional em detrimento das variações nos ciclos de glaciação e deglaciação. Essas mudanças produziram formas e processos superficiais diferentes dos atuais. A resposta a essas mudanças foi a conservação de morfologias reliquiais, heranças de ambientes com fisionomias bastante diferenciadas. Segundo Moura (2003), a análise integrada desses elementos morfológicos constitui a base para uma tentativa de compreensão da sequência evolutiva da paisagem ao longo da sua história geológica recente.

Segundo Ferreira (2010), Santos (2007), Silva (2007), Corrêa (1997 e 2001), Barreto (1993 e 1996), a busca pelo entendimento da evolução geomorfológica do Nordeste Brasileiro não é recente, ela remonta ao início do século XX, quando diversos pesquisadores passaram a estudar a temática da região semi-árida brasileira. No entanto, esses estudos eram prioritariamente regionalistas, deixando uma lacuna nas abordagens de maior escala. A região do Vale do São Francisco ganhou destaque pela presença de depósitos eólicos de variadas dimensões ao longo do sub-médio curso do rio. Esses pacotes sedimentares foram sendo estudados ao longo de todo o século XX, com grande destaque para os trabalhos realizados por Williams (1925), pioneiro nos estudos, King (1956), Tricart (1974), Goudie (1983), Barreto (1993, 1996) e Ab `Sáber (2006).

Os depósitos e feições eólicas representam importantes componentes dos modelados do relevo. Dentre esses conjuntos de acumulações sedimentares e morfologias, têm grande destaque na inferência de condições paleoambientais os campos de dunas fixadas, fixas, fósseis, reliquiais ou inativas. essas feições podem representar registros de mudanças climáticas acentuadas, eventos de maior aridez ou intensificação dos ventos durante o Quaternário. Esses sistemas dunares têm sido abordados nos estudos paleoambientais, baseados em critérios sedimentológicos e geomorfológicos, contribuindo para a aferição de paleoeventos de expansão das áreas áridas e mudanças no padrão de circulação atmosférica global (BARRETO, 1996).

Apesar de sua importância no estudo da evolução ambiental da região semi-árida brasileira ao longo do Quaternário, a presença de depósitos eólicos inativos na margem pernambucana do São Francisco nunca havia sido relatada. Diante disso, o presente estudo teve como objetivo, a realização de um mapeamento geomorfológico, caracterização sedimentológica e posicionamento geocronológico dos depósitos eólicos localizados no município de Floresta, margem pernambucana do Lago de Itaparica, Nordeste do Brasil.

\section{A ÁREA DE ESTUDO}

\section{Localização}

A área de estudo localiza-se às margens do Lago de Itaparica no Município de Floresta (fig. 01), está inserida no contexto da Depressão Sanfranciscana. Compreende uma ampla planície assimétrica com aproximadamente $12 \mathrm{~km}$ de eixo norte $/$ sul e $08 \mathrm{~km}$ no eixo leste/oeste, cerca de $8 \mathrm{~km}^{2}$. 
Figura 01. Mapa de localização da área

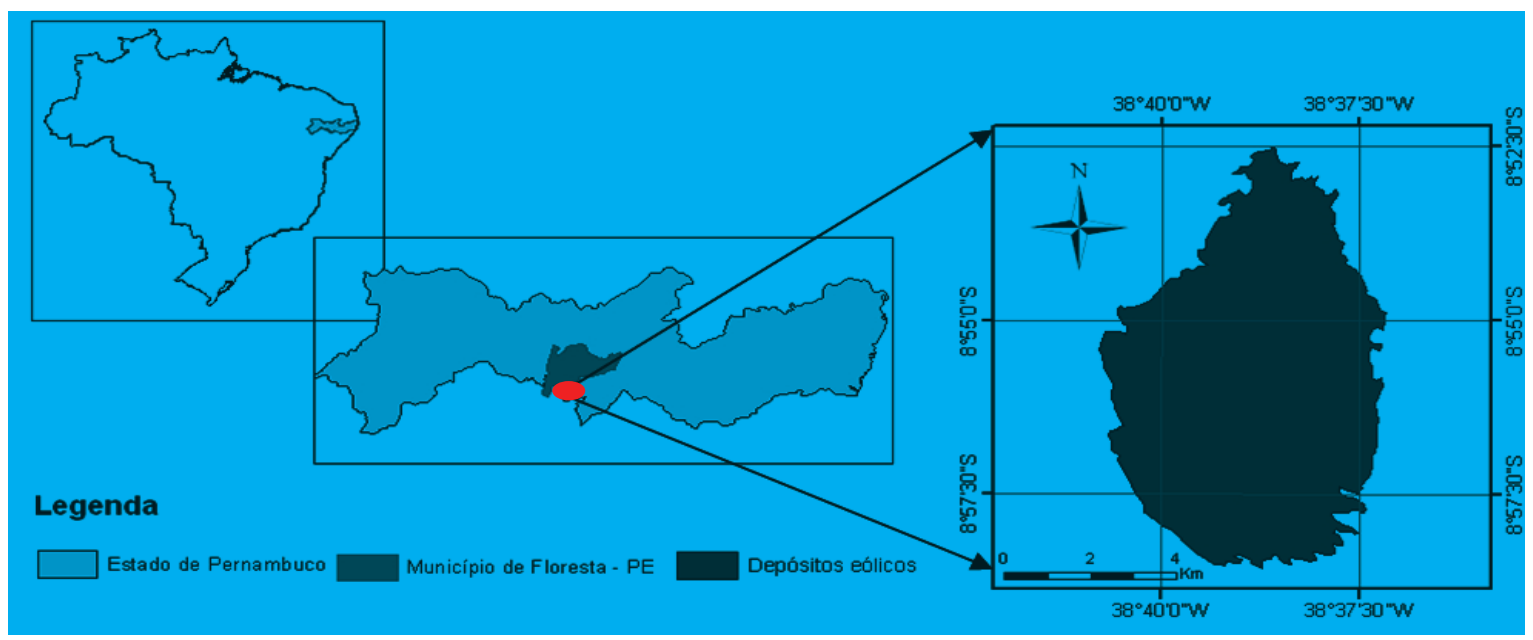

Org. dos autores.

A Geologia da área compreende as coberturas superficiais quaternárias que repousam discordantemente sobre as rochas metamórficas Mesoproterozói- cas do Complexo Belém de São Francisco (fig. 02) (CPRM (2001).

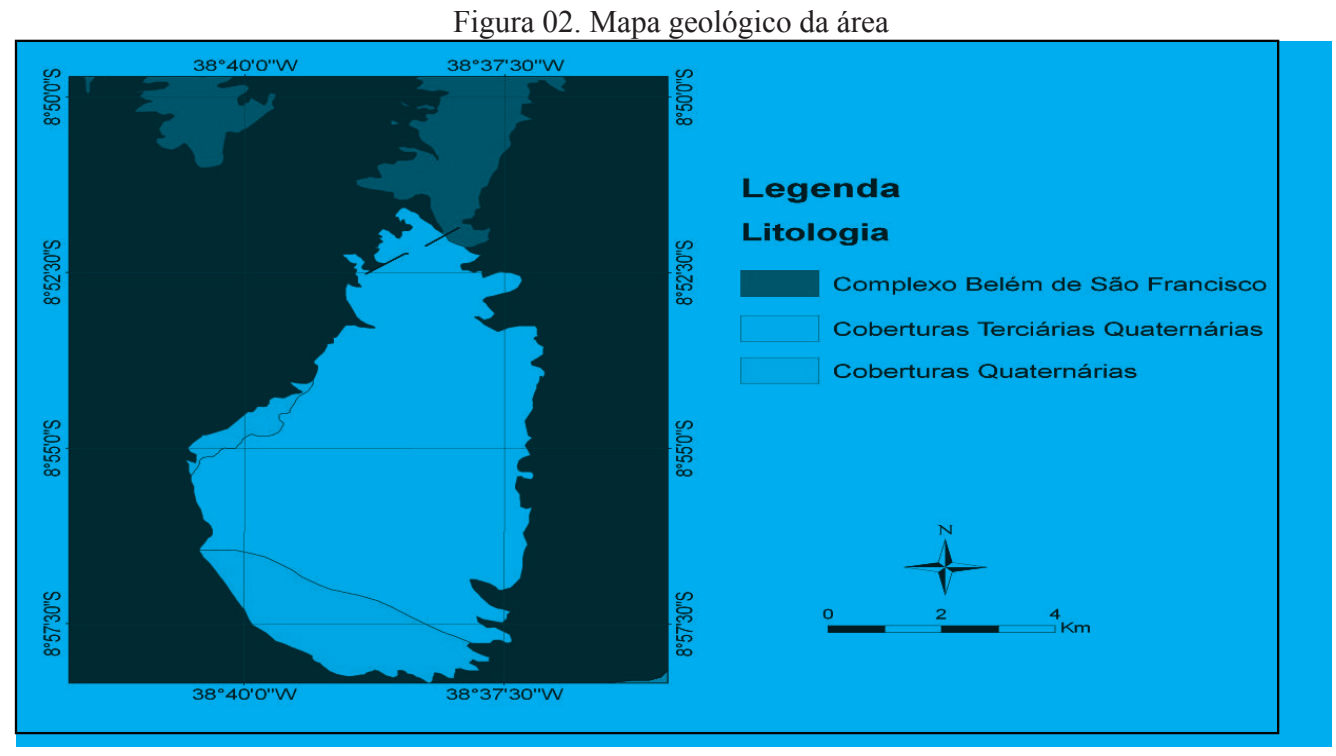

Fonte: CPRM 2001. Org. dos autores.

O Complexo Belém do São Francisco, definido por Santos $(1995,2000)$ é constituído por ortognaisses e migmatitos com restos de supracrustais. Predominam metaleucogranitos róseos e migmatitos que englobam restos de ortognaisses tonalíticos-granodioríticos e supracrustais do Complexo Cabrobó. Os migmatitos possuem estrutura do tipo chlieren, nebulítica e raft, sugerindo anatexia in situ (SANTOS, 1999).
Sua área tipo localiza-se entre os municípios de Belém do São Francisco e Floresta, região onde Lima et al. (1985) obtiveram uma isócrona $\mathrm{Rb}-\mathrm{Sr}$ (rocha total) de aproximadamente $1.070 \mathrm{Ma}$ (CPRM 1999).

Os depósitos neocenozóicos foram mapeados pelo CPRM (1999) como sendo formados por sedimentos inconsolidado derivados da ação fluvial 
do rio Pajeú em seu encontro São Francisco. Nesse mapeamento realizado pelo CPRM, as formações neocenozóicas foram descritas sem maiores detalhes de forma bem generalizada para a região.

Ferreira (2010) baseado em dados sedimentológicos, morfológicos e geocronológicos, descreveu os depósitos neocenozóicos como sendo o retrabalhamento eólico dos sedimentos fluviais depositados no baixo curso do rio Pajeú. Esse pacote arenoso é formado por areias médias a finas, bem selecionadas, derivadas do transporte eólico a que foram submetidas. Apresentam ainda, características do transporte hidráulico, já que sua área fonte foram os terraços fluviais do São Francisco.

\section{Geomorfologia}

A Geomorfologia da região compreende um mosaico formado por pedimentos, maciços residuais e inselbergs (fig. 03). Os pedimentos representam áreas moderadamente planas, onde assentam-se os depósitos Quaternários. Essas áreas foram descritas de forma muito generalizada, como apresentando topografia pouco movimentada, sobre a qual se formam pavimentos detríticos por remoção das fácies mais finas, mediante a atuação da erosão laminar (RADAM BRASIL, 1973).

Figura 03. Superfícies pedimentadas e inselbergs a norte da área estudada

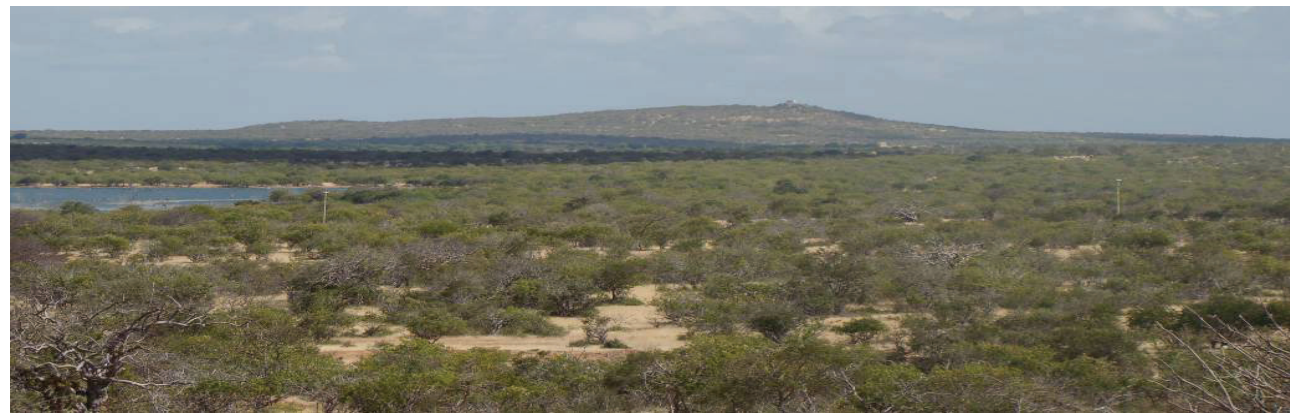

Foto dos autores.

A norte da área encontram-se distribuídas formas residuais, maciços e inselbergs, corpos isolados, delimitados por encostas íngremes sob a influência, sobretudo, do intemperismo físico. Esses morros isolados, em virtude do gradiente de suas encostas, encontram-se sujeitos a intensos processos denudacionais, por vezes, com formação de depósitos de tálus e colúvios em suas bases.

\section{Condições Climáticas}

Segundo o Plano Estadual de Recursos Hídricos do Estado de Pernambuco - PERHPE (1998), a região Nordeste possui pelo menos seis sistemas atmosféricos: a Zona de Convergência Inter Tropical - ZCIT (dando origem a dois sistemas distintos, a massa equatorial continental - $\mathrm{mEc}$ e a massa equatorial atlântica - mEa), Frente Polar Atlântica - FPA; as Ondas de Leste - OL; Vórtices Ciclônicos da Atmosfera Superior - VCAS e; as brisas terrestres e marinhas com suas oscilações mensais e bimensais.

No vale do são Francisco a distribuição pluviométrica é bastante irregular, com forte concentração de chuvas no verão, geradas principalmente pela ZCIT. Os meses mais chuvosos são março e abril apresentando médias mensais acima dos $120 \mathrm{~mm}$ (fig. 02). Os mais secos são agosto e outubro com volumes pluviométricos abaixo dos $10 \mathrm{~mm}$ milímetros. A temperatura média mensal é de $26.4{ }^{\circ} \mathrm{C}$, com pouca variação ao longo do ano, as temperaturas mais baixas e mais elevadas nos são meses de agosto e janeiro respectivamente. 
Figura 02. Climograma do Município de Floresta.

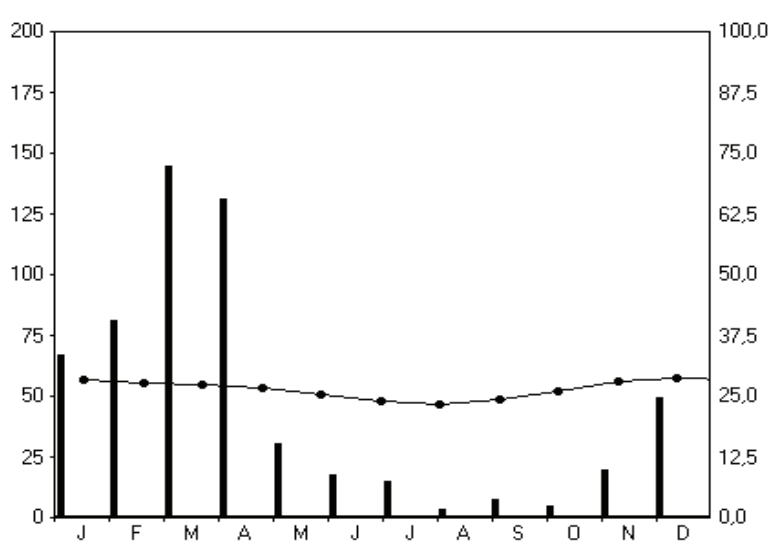

Fonte: Depto. de Ciências Atmosféricas - DCA - UFCG (2010)

Os ventos predominantes na região são os alísios de sudeste (Fig. 05) gerados pelo Anticiclone do Atlântico Sul formado pela circulação das células de Hadley nas imediações do trópico de capricórnio.
Essas rajadas de ventos têm grande influência na circulação atmosférica do Nordeste do Brasil, são eles que vão comandar a intensidade das massas de ar que geram as precipitações sobre a região.

Figura 05. Direção predominante dos ventos no Sub-Médio São Francisco no estado de Pernambuco.

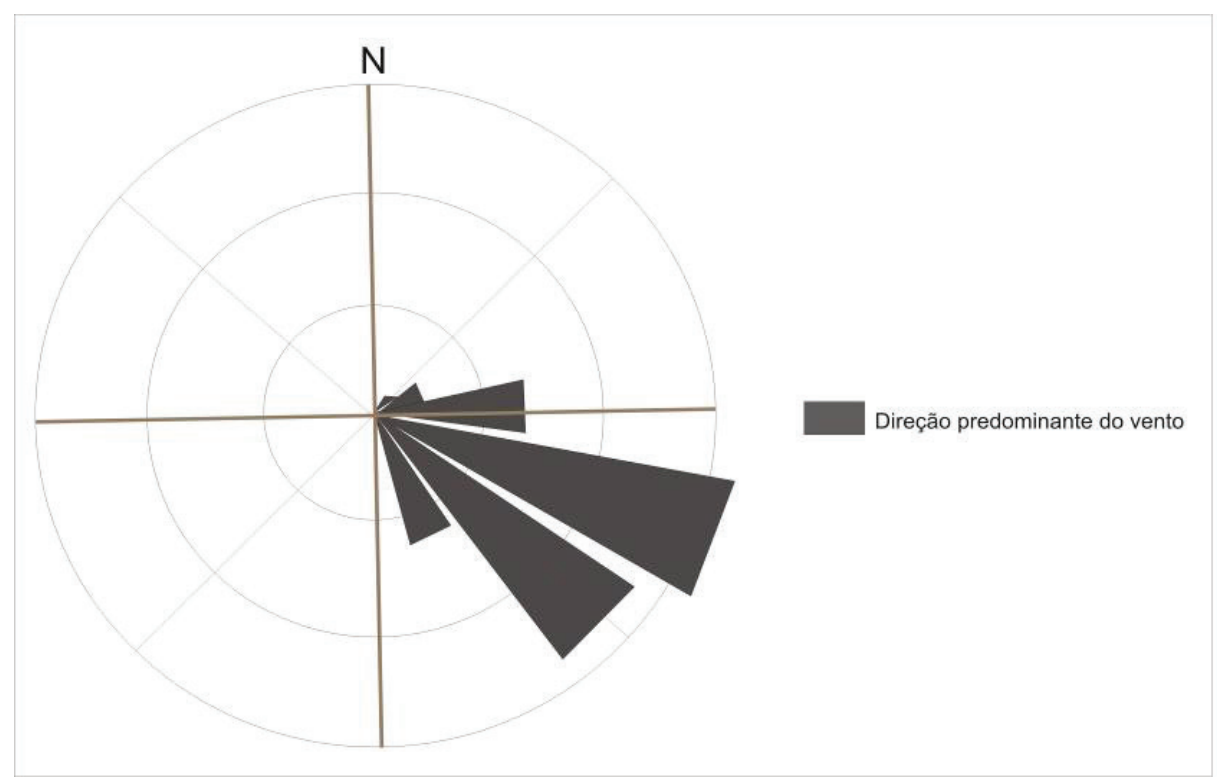

Fonte: Eletrobrás (2008).

$\mathrm{Na}$ faixa litorânea esses ventos vão deslocar a Frente Polar Atlântica que em momentos de maior magnitude consegue adentrar também ao vale do São Francisco, chegando até o cotovelo de Cabrobó (SEREBRENICK, 1953), levando frio para a região. Esses ventos vão exercer também influência sobre o deslocamento da zona de Convergência Intertropical e a massa equatorial continental, principais agentes de geração de precipitação sobre a região semi-árida brasileira.

\section{Hidrografia}

A área estudada localiza-se na confluência de duas grandes bacias hidrográficas, São Francisco 
e Pajeú. O rio São Francisco nasce nas encostas da Serra da Canastra no estado das Minas Gerais e corta grande parte da região semi-árida brasileira com seu regime perene. O Rio Pajeú nasce nas encostas íngremes das cimeiras do Planalto da Borborema no Estado da Paraíba, apresenta regime intermitente e corta perpendicularmente o estado de Pernambuco em sua porção semi-árida.

Nas últimas décadas a bacia do São Francisco vem passando por grandes intervenções antropogênicas, devido principalmente à construção de grandes represas. Em 1988, o rio São Francisco foi represado para a construção do Lago de Itaparica, alagando as suas margens e as desembocaduras de seus tributários, entre eles o Rio Pajeú. Esse espelho d'água ocupa uma área bastante aplainada, estruturada sobre a Depressão Sanfranciscana e suas águas afogaram as planícies e terraços fluviais desses rios.

Atualmente a região vem passando por grandes transformações devido à integração de grandes bacias hidrográficas semi-áridas. A construção dos canais que levarão as águas do São Francisco aos estados de Pernambuco, Ceará, Paraíba e Rio Grande do Norte vem gerando grandes transformações paisagísticas e sócio-econômicas regionais. Os impactos dessas intervenções ainda não podem ser mensurados, no entanto, a previsão é de que gere grandes alterações nas formas de uso das terras na região.

\section{Cobertura Vegetal}

Ab 'Sáber (1974) chama atenção para a originalidade fitogeográfica do Nordeste brasileiro, mais especificamente para a sua área central, onde ocorrem tipos complexos de caatingas, bastante diferentes das coberturas vegetais das outras regiões semi-áridas do continente sulamericano.

A vegetação da área estudada (fig. 06) é a caatinga hiperxerófila, caracterizada por uma cobertura arbustiva bem adaptada ao clima semi-árido. Seus principais representantes são: o pereiro (Pera glabata); a faveleira (Jatropha phyllacantha); a braúna (Melanoxylon brauna); a aroeira (Shhinus mole); o angico (Piptadenia calubrina); a catingueira (Caesalpina sp.); o pião bravo (Jatropha herbácea); a jurema (Pithecolobium tortuni); a quixabeira (Bumelia sertorum); a barriguda (Cavanilesia arbórea).

Figura 06. Vegetação de caatinga no campo de dunas de Floresta

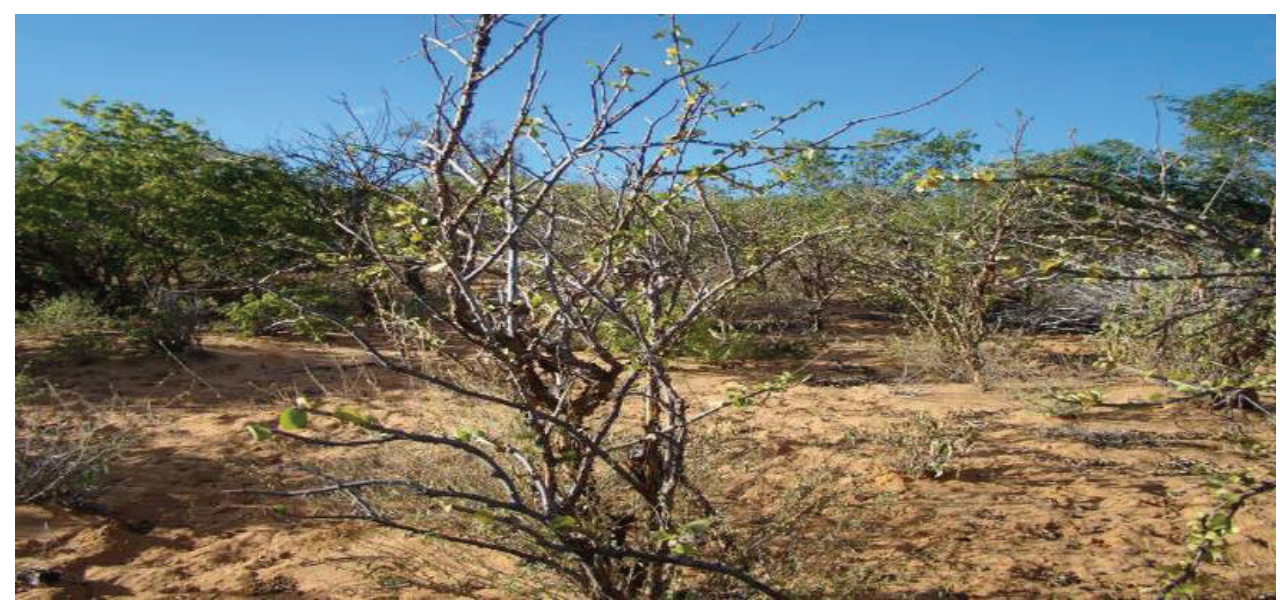

Foto dos autores.

\section{METODOLOGIA}

Realizou-se intensa revisão bibliográfica, buscando referenciais teóricos e técnicas de aprimoramento das metodologias empregadas. Foram revisados estudos que tratam das temáticas: Geologia; Sedimentologia e Geomorfologia da região de Itaparica.

Levantamento de documentos e dados cartográficos para elaboração dos mapas temáticos. Foram obtidas imagens de satélite, cartas topográficas, foto-

Soc. \& Nat., Uberlândia, 25 (2): 363-378, mai/ago/2013 
grafias aéreas e dados de radar.

Realizou-se visita técnica a campo para coleta de dados e correção dos modelos cartográficos elaborados em gabinete. A área foi amplamente percorrida com georreferenciamento de pontos de amostragens para correções cartográficas e coletas de amostras para análises sedimentológicas e geocronológicas.

Para realização do mapeamento geomorfológico utilizaram-se os dois primeiros níveis de caracterização geomorfológica de abordagem propostos por Ab'Saber (1969): a compartimentação topográfica e estrutura superficial da paisagem.

Foram adotados os procedimentos morfométricos e cartográficos recomendados pela União Geográfica Internacional - UGI, utilizando quatro níveis de abordagem: a morfometria - altimetria, dimensões, desníveis, extensões; a morfologia - formas do perfil, concavidades, convexidades, retilineidades, rupturas, topos, fundos de vale, etc; a gênese - degradação ou agradação; a cronologia relativa - idades das formas (DEMEK 1972; RODRIGUES, 1998; CORRÊA, 2001; SANTOS, 2007; SILVA, 2007). Como produto final, elaborou-se um mapeamento em micro escala.

Os procedimentos operacionais consistiram no levantamento de material cartográfico e de imagens de sensores orbitais. Apoiando-se principalmente em mapas geológicos, imagens de satélite, dados de radar e cartas topográficas foram identificados unidades morfoestruturais e morfoclimatológicas. Essas unidades morfoclimáticas foram subdivididas em unidades morfológicas menores. Gerou-se então, um mapa geomorfológico na escala de 1:25.000, compatível com as recomendações da UGI.

Foram coletadas dez amostras, seguindo os procedimentos adotados por Barreto (1996) e Santos (2008), para análises sedimentológicas e três para a realização de datações. As amostras para sedimentologia foram coletadas, cerca $1,0 \mathrm{~kg}$ e embaladas em sacos plásticos transparentes com identificação.

Em laboratório as amostras foram secas em estufa a $90{ }^{\circ} \mathrm{C}$, quarteadas, peneiradas e pesadas $100 \mathrm{~g}$ em balança de precisão. Realizou-se dois tipos de peneiramentos, um úmido, utilizando uma peneira com abertura de $0,062 \mathrm{~mm}$ e outro seco, com utilização de uma seqüência de cinco peneiras, levadas ao agitador por dez minutos. Posteriormente, após os peneiramen- tos, as frações granulométricas foram individualmente pesadas para o calculo de seus respectivos percentuais no conjunto da amostra.

Foram coletadas 3 amostras para datação pelo método da Luminescência Opticamente Estimulada (LOE), utilizando-se tubos plásticos de cor preta (PVC), com $45 \mathrm{~cm}$ de comprimento e $40 \mathrm{~mm}$ de diâmetro. Os afloramentos foram limpos, com retirada de aproximadamente $1 \mathrm{~m}$ do capeamento para que os tubos fossem introduzidos horizontalmente em níveis das seções colunares. As amostras foram embaladas e enviadas para datação no Laboratório de Vidros e Datação da Faculdade de Tecnologia de São Paulo FATEC-SP.

\section{RESULTADOS E DISCUSSÃO}

\section{Mapeamento Geomorfológico}

A geomorfologia da área é pouco complexa, desenvolvida sobre uma morfoestrutura denominada de Planície de Acumulação Eólica - PAE (fig. 04). Essa unidade se desenvolveu sobreposta a terrenos cristalinos neoproterozóicos da Faixa de dobramento Riacho do Pontal e suas unidades morfoesculturais estão descritas a seguir:

\section{Planície de Acumulação Eólica - PAE}

A unidade morfoestrutural, Planície de acumulação eólica, consiste em uma extensa planície sobreposta a superfícies pedimentares da depressão Sanfranciscana (FERREIRA, 2010). Esse conjunto geomorfológico apresenta duas unidades morfoesculturais bem distintas, a Planície de Acumulação Eólica Dunar (PAED) e a Planície de Acumulação Eólica Retrabalhada (PAER). Esses conjuntos morfológicos se desenvolveram através do retrabalhamento eólico dos sedimentos das planícies e terraços fluviais do São Francisco. Sua compartimentação está descrita a seguir: 


\section{Planície de Acumulação Eólica Dunar - PAED}

Essa unidade corresponde às morfologias formadas por edifícios dunares distribuídos ao sul da
PAE e apresenta 2 conjuntos morfológicos descritos a seguir:

Figura 07. Mapeamento Geomorfológico do campo de dunas de Floresta
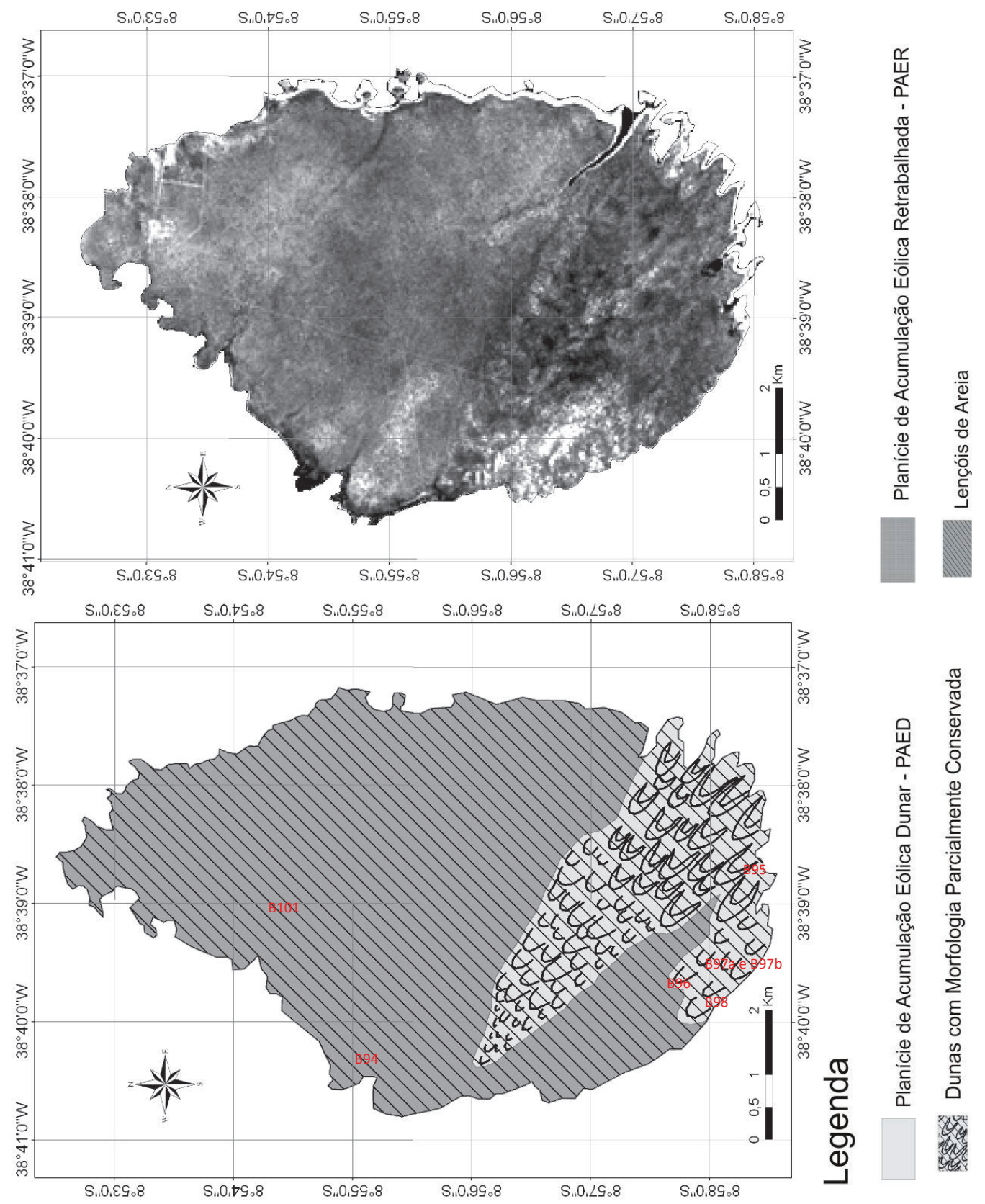

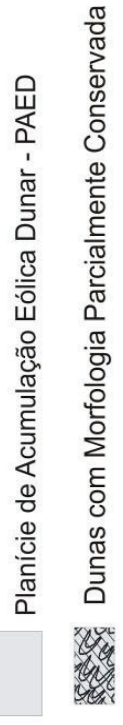

Org. dos autores.

Soc. \& Nat., Uberlândia, 25 (2): 363-378, mai/ago/2013 
Dunas com Morfologia Parcialmente Conservada-edifícios dunares, distribuídos na parte central e margem leste da PAED, apresentam morfologia parabólica e altitudes médias de cerca de $40 \mathrm{~m}$ em relação ao nível de base circundante. Essas dunas vêm sendo retrabalhadas pelos processos morfodinâmicos locais, caracterizados por chuvas concentradas e de média a grande intensidade, gera intensa atividade morfodinâmica denudacional. Como resposta, ao desencadeamento das atividades erosivas, parte de suas morfologias originais vem sendo dissecadas (Fig. 08).

Figura 08 - Dunas parabólicas inativas com morfologia parcialmente conservada, localizadas na faixa leste da PAED

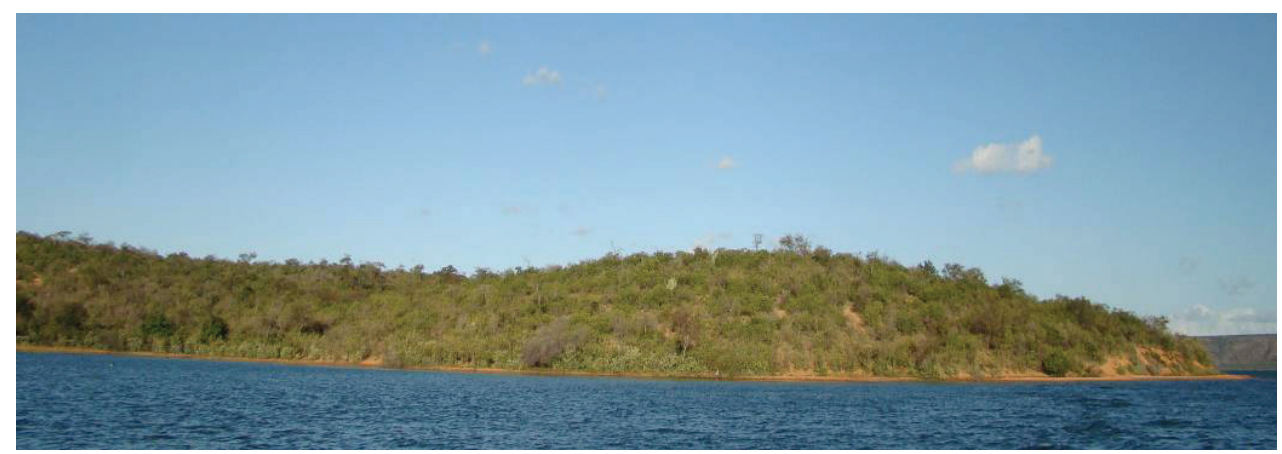

Foto dos autores.

Planície de Acumulação Eólica Retrabalhada PAER

Essa unidade corresponde a uma ampla área arenosa levemente ondulada, formada por morfologias monótonas distribuídas a norte da PAE, cujo conjunto morfológico está descrito a seguir:

Lençóis de Areia - são amplas superfícies arenosas, com morfologia suave ondulada, localizadas na borda norte da PAE (Fig. 08). Relevo monótono e pouca variação altimétrica recortado pelos canais de drenagem efêmeros. $\mathrm{O}$ aumento da umidade no inicio do Holoceno possibilitou o desenvolvimento de uma vegetação mais densa de caatinga, diminuindo a eficiência da movimentação eólica, levando a estabilização das areias e contribuindo para sua conservação frente aos intensos processos morfodinâmicos locais.

Figura 10. Lençóis areia na parte norte da PAER.

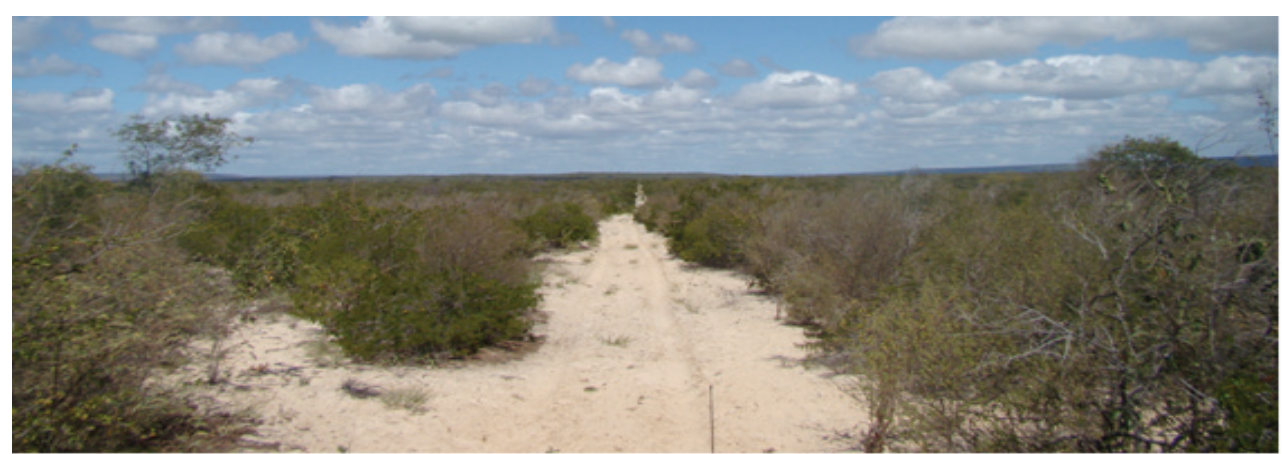

Foto dos autores. 


\section{Padrão morfológico e direção atual dos ventos}

O vento é um importante agente geológico, bastante eficaz no transporte e deposição de partículas sedimentares. As areias são sopradas pelo vento sem a contribuição de fluxos hídricos, dando origem a depósitos bem selecionados. O transporte se dá por suspensão das partículas finas $(0,05 \mathrm{~mm})$ e rolamento, grânulos maiores $(2,0 \mathrm{~mm})$. As partículas maiores são movimentadas pelo impacto de outras partículas em saltação (Suguio, 1980). O resultado dessa movimentação é a formação de campos de dunas.

A formação e fixação desses depósitos arenosos é condicionada por algumas características ambientais bem definidas. O clima não é o único fator responsável pela formação desses pacotes sedimenta- res, a dinâmica natural dessas áreas está muito ligada à existência de uma área fonte, da falta de competência da cobertura vegetal e da intensa ação do vento frente ao relevo.

A configuração topográfica da Bacia do São Francisco, tendo o planalto da Borborema e o Planalto do Jatobá como barreiras orográficas em seus baixo e sub-médio curso, canaliza os alísios de sudeste, fazendo com que as rajadas de ventos adentrem pelo vale do rio, movimentando as areias de suas margens, o que possibilitou a formação de depósitos eólicos em suas margens durante o Pleistoceno tardio. Essa configuração topográfica canaliza os ventos na direção sudeste noroeste (Fig. 12).

Figura 12. Medidas de direção do eixo axial e padrão morfológico das dunas parabólicas, sobrepostas a atual direção média dos ventos na região

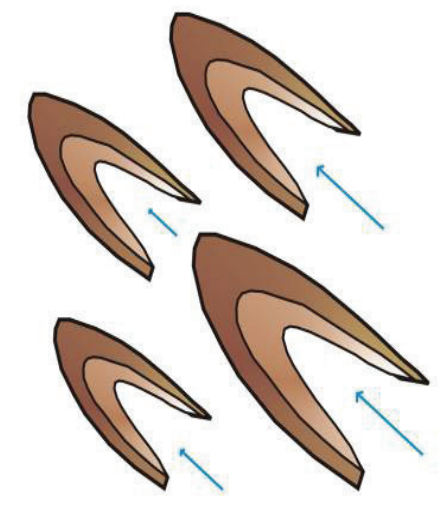

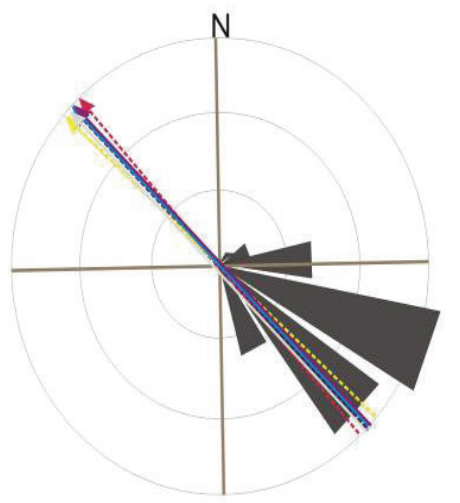

Org. dos autores.
Direção predominante do

Direção das dunas com morfologia Parcialmente Conservada
Foram realizadas medidas nos eixos axiais de 20 edifícios dunares para aferir a as paleodireções do vento durante o período de deposição. Sobrepondo-se essas paleodireções tanto das dunas à atual circulação dos ventos na área, é possível observar que elas coincidem. Essa configuração na circulação dos ventos na calha do São Francisco pode ter se mantido desde o início do processo deposicional até os dias atuais, fortemente influenciadas pela configuração do relevo regional. Outro elemento que corrobora com essa ideia é que comparando as paleodireções de vento observadas por Barreto (1993 e 1996) a montante da área, observa-se pouca variação na direção dos eixos deposicionais, predominando a direção sudeste noroeste, concordante com atual direção dos alísios.

\section{SEDIMENTOLOGIA E GEOCRONOLOGIA}

\section{Características granulométricas e morfoscópicas}

A seção estratigráfica (fig. 10), descrita em corte de duna na PAED, mostra que esses depósitos apresentam cor avermelhada, estrutura maciça, granulometria média à fina e compactação moderada.

As amostras de sedimentologia foram processadas e apresentaram os seguintes resultados: em relação à distribuição das classes modais, os valores obtidos, quando plotados no diagrama de Shepard 
(1954), mostram sedimentos compostos por areia fina (Fig. 11); quanto ao grau de seleção, os resultados mostram amostras moderadamente selecionadas. Isso se dá pela seleção natural quando do transporte eólico que vai movimentando os grânulos menores em suspensão $(0,05 \mathrm{~mm})$, os intermediários por saltação (2,0mm). As partículas maiores são movimentadas pelo impacto de outras partículas em saltação (Suguio, 1980)

Figura 13 - Seção estratigráfica dos depósitos eólicos da margem do Lago de Itaparica

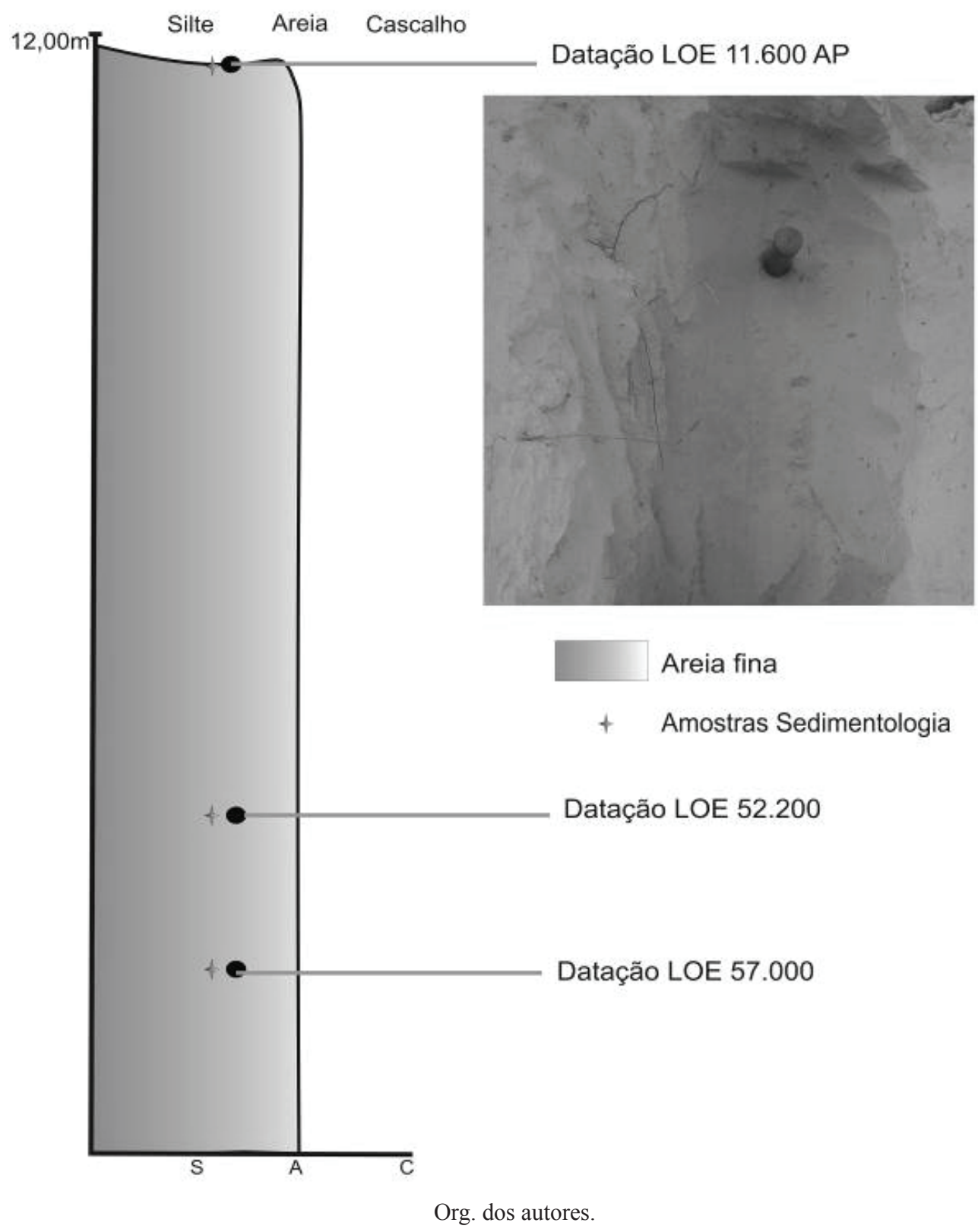

Soc. \& Nat., Uberlândia, 25 (2): 363-378, mai/ago/2013 
Os dados de assimetria mostram grânulos com valores variando entre aproximadamente simétricos e positivos, gerando uma concentração dos grossos e uma calda de finos (Fig. 12). No entanto, na área estudada esses valores são muito variáveis, já que as áreas fontes desses depósitos são os depósitos sedimentares do São Francisco, terraços e planícies fluviais. Nesse caso os dados obtidos podem refletir a assimetria do transporte fluvial e não da deposição eólica.
Quanto à curtose, segundo Folk e Ward (1957), os resultados mostram valores variando entre o caráter de bimodalidade e polimodalidade dos depósitos. Seguindo o modelo proposto pelos autores, as amostras apresentam valores de classificação variando de Platicúrtica a Leptocúrticas.

Figura 14 - Digrama de Shepard para amostras dos depósitos eólicos

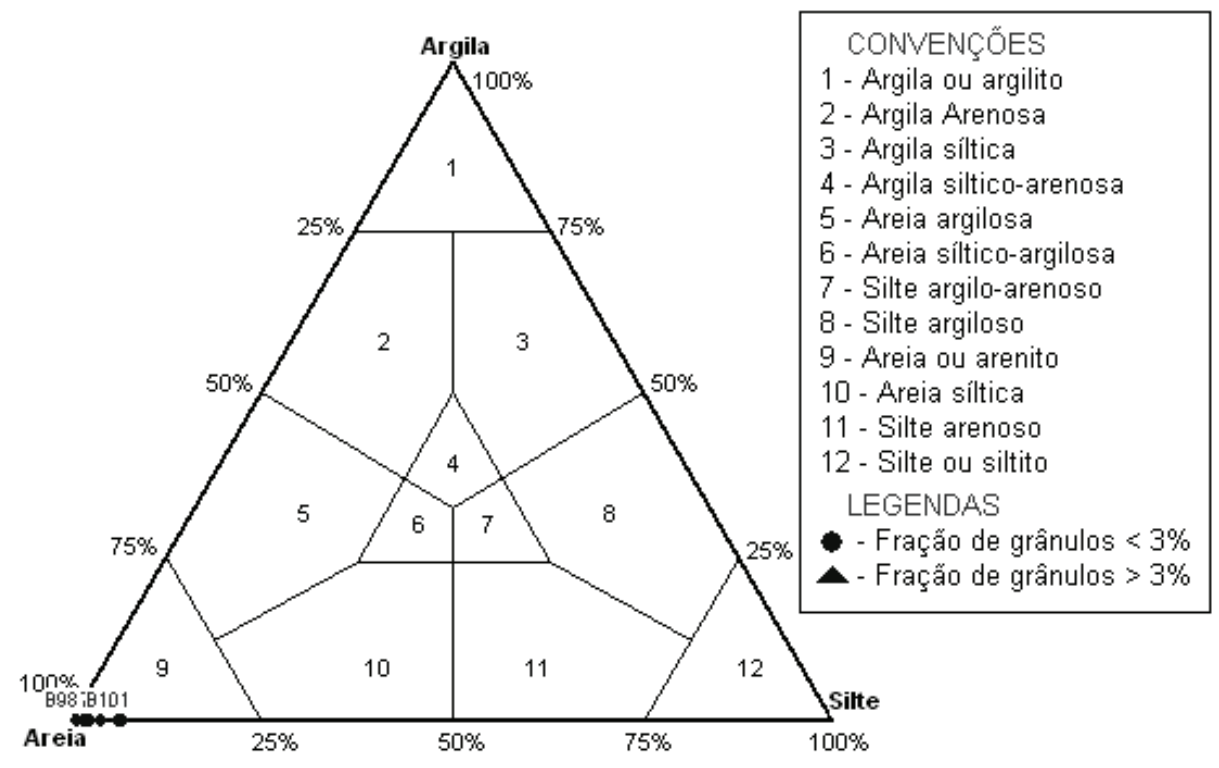

Org. dos autores.

Figura 15 - Distribuição da freqüência acumulada da fração areia dos depósitos eólicos

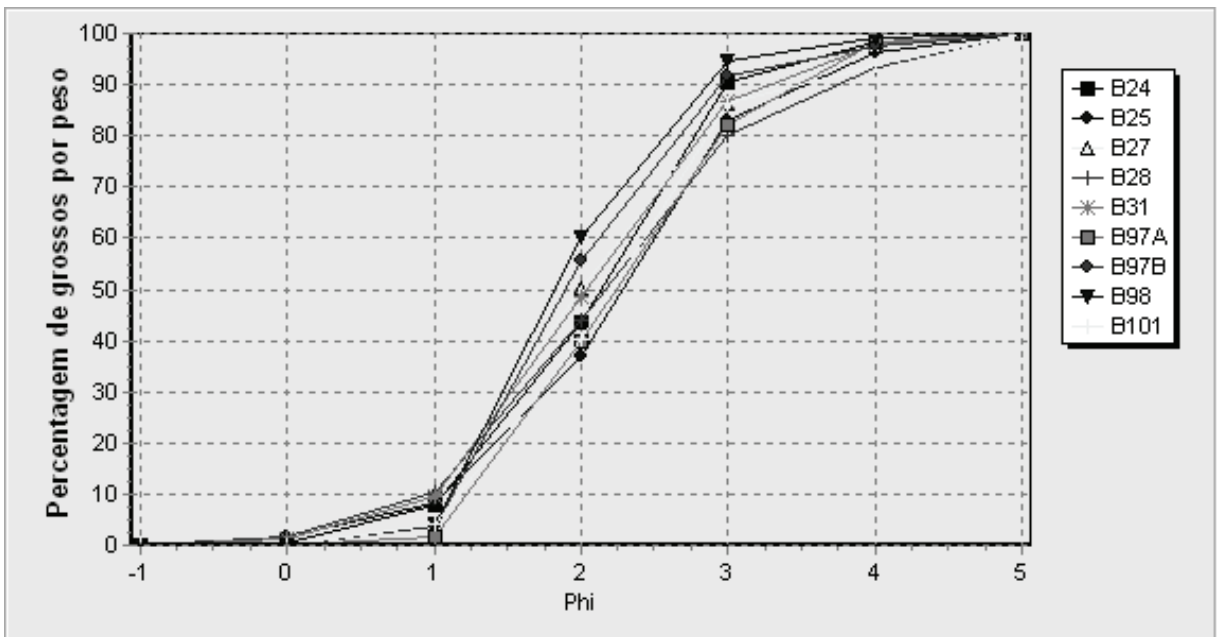

Org. dos autores. 
Os dados de morfoscopia (Tab. 01) mostram que os depósitos apresentam predominância do tipo EL, rolados em meio aquoso, diferentemente do que seria esperado para depósitos eólicos. No entanto, a área fonte das areias, o rio, justifica os resultados obtidos, tratando-se de sedimentos fluviais retrabalhados por ação eólica.

Tabela 01. Resultados das análises morfoscópicas e granulométricas dos depósitos eólicos

\begin{tabular}{|c|c|c|c|}
\hline Amostra & Dose Anual ( $\mu$ Gy/ano) & Dose Acumulada LOE (Gy) & Idade LOE (anos) \\
\hline B97a & $1.270 \pm 80$ & 66,35 & $52.200 \pm 6.000$ \\
\hline B97b & $1.320 \pm 90$ & 75,7 & $57.000 \pm 6.500$ \\
\hline B98 & $930 \pm 150$ & 10,87 & $11.600 \pm 2500$ \\
\hline
\end{tabular}

Org. dos autores.

O grau de esfericidade mostra predominância da classe discoidal, sedimentos que foram rolados por longas distâncias na bacia do São Francisco.

Os índices de rolamento segundo a escala de Powers (1953, apud Suguio, 1980), mostram que sedimentos eólicos apresentam variação de grânulos angulosos a sub-angulosos, resultantes de impactos durante o transporte eólico, que retrabalhou parcialmente as superfícies arredondadas derivadas do transporte fluvial.

\section{Geocronologia}

Quanto à geocronologia desses depósitos, foram datadas 3 amostras por LOE (Fig. 13), coletadas em corte de uma duna. Os resultados mostram (tab. 02) que o nível próximo ao atual nível de base circundante, o lago de Itaparica, a deposição ocorreu no Pleistoceno tardio, aproximadamente 57.000. O nível intermediário, cerca de $1,2 \mathrm{~m}$ acima, apresenta idade de 52.000 anos, ainda no Pleistoceno. Já o atual topo da deposição, corresponde à transição Pleistoceno/Holoceno, aproximadamente 11.800 anos. Essas idades mostram que a atividade eólica se deu durante o Pleistoceno Tardio e teria cessado na transição para o Holoceno.

Tabela 02- Depósitos eólicos com datação por LOE

\begin{tabular}{|ccccccc|}
\hline & Unidade morfo- & \multicolumn{2}{c}{ Morfoscopia } & \multicolumn{2}{c|}{ Índice de Rolamento } \\
Amostra & lógica & Tipo & $\%$ & Classe & $\%$ & Grau de Selecionamento \\
& & & & & \\
B94 & Lençol de areia & EL & 48 & subarredondada & 43 & Moderadamente selecionado \\
\hline B95 & Lençol de areia & EL & 65 & subarredondada & 45 & Moderadamente selecionado \\
\hline B96 & Lençol de areia & EL & 60 & subangulosa & 60 & Moderadamente selecionado \\
\hline B97A & Duna & EL & 42 & subangulosa & 55 & Moderadamente selecionado \\
\hline B97B & Duna & EL & 48 & subangulosa & 58 & Moderadamente selecionado \\
\hline B98 & Duna & EL & 40 & subangulosa & 65 & Moderadamente selecionado \\
\hline B101 & Lençol de areia & EL & 46 & angulosa & 45 & Moderadamente selecionado \\
\hline
\end{tabular}

Org. dos autores. 
Sobrepondo-se as idades obtidas com a LOE à curva de estágios isotópicos do Pleistoceno (fig.
13), observa-se que a atividade eólica na área está relacionada ao Último Máximo Glacial.

Figura 13. Curva de variação do nível médio dos mares com idades LOE e idades TL obtidas por Barreto 1997.

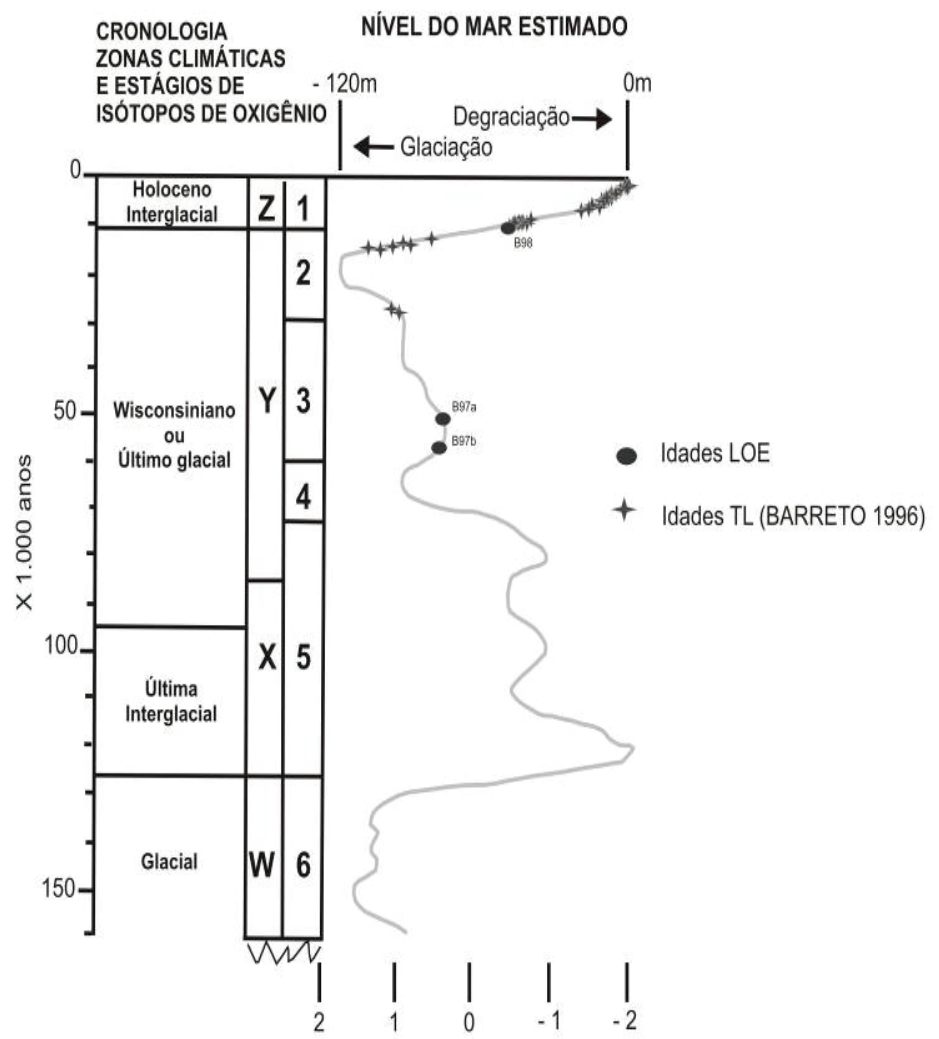

Fonte: Adaptado do modelo de Ericson e Wollin, 1968

As idades obtidas foram comparadas com as apresentadas por Barreto (1993 e 1996) que realizou mais de 40 datações por termoluninescência no campo de dunas inativas, entre Pilão Arcado e Barra, Bahia, com cerca de $7.000 \mathrm{~km}$ de extensão. Os valores em ambas as áreas mostram que a deposição eólica ocorreu no Pleistoceno tardio e pelo menos até a transição Pleistoceno-Holoceno. Na Bahia, a movimentação eólica continua até hoje, enquanto que em Pernambuco, ela teria cessado no inicio do Holoceno. Essa diferenciação pode estar ligada a uma condição de maior umidade na área de Itaparica ou a mudanças na taxa de suprimento de sedimentos do São Francisco no Holoceno.

\section{CONCLUSÕES}

Estudos que fazem referência a presença de depósitos eólicos interiores na Bacia do Rio São
Francisco vem sendo desenvolvidos desde o inicio do século XX. Com o passar do tempo e o desenvolvimento de novas metodologias e tecnologias, esses estudos vem sendo revisitados e aprofundados. As revisões bibliográfica e cartográfica realizadas, mostram que ao longo do tempo vem se intensificando as tentativas de reconhecimento do passado geológico recente da região.

As condições paleoclimáticas da região do vale do São Francisco possibilitaram a formação de campos de dunas nos estados da Bahia e Pernambuco. A área fonte dessas areias foi o próprio rio São Francisco que drena importantes fontes de material arenoso, como: as encostas íngremes da Serra da Canastra no estado de Minas Gerais; a borda oeste da Chapada Diamantina e; a Bacia Sedimentar do São Francisco no estado da Bahia, além da borda sudeste da Bacia Sedimentar do Parnaíba no estado do Piauí.

As idades LOE mostram que o ciclo de ati-

Soc. \& Nat., Uberlândia, 25 (2): 363-378, mai/ago/2013 
vidade eólica iniciou-se pelo menos no Pleistoceno Tardio, durante o Último Máximo Glacial. A fixação das dunas, nas margens de Itaparica teria ocorrido na transição Pleistoceno/Holoceno quando a maior umidade possibilitou um adensamento da cobertura vegetal. As idades obtidas em Pernambuco são correlacionáveis com as obtidas por Barreto (1996) no campo de dunas inativas entre Pilão Arcado e Barra no estado da Bahia, demonstrando ligação entre o dois processos de deposição eólica.

O posicionamento cronológico associado à distribuição morfológica dos edifícios dunares, mostra que do Pleistoceno Tardio ao Holoceno, a circulação dos alísios de sudeste não variou significativamente no vale do São Francisco. Isso se deu pela forte canalização do vento frente ao relevo e possibilitou a energia necessária para o retrabalhamento eólico dos depósitos aluviais do São Francisco, dando origem ao campo de dunas.

No campo de dunas de Floresta, PE assim como entre Pilão Arcado e Barra, o processo de fixação das dunas está relacionado a mudanças no padrão climático e se deu pelo desenvolvimento de uma vegetação mais densa que se estabeleceu no Holoceno, quando as a velocidade dos ventos ficou mais amena. Essa amenização climática, com evidências de maior umidade sobre a região durante a transição Pleistoceno/Holoceno, foi observada por De Oliveira et al, 1999 ou 2000?) em estudo palinológico realizado no campo de dunas entre Pilão Arcado e Barra, Bahia.

\section{REFERÊNCIAS}

AB'SÁBER, A. N. Um conceito de geomorfologia a serviço das pesquisas sobre o Quaternário. Geomorfologia. n. 18, IG-USP, S. Paulo. 1969.

AB'SABER, A. N. O domínio Morfoclimático Semi-árido das Caatingas Brasileiras. Geomorfologia 43: 1-39. 1974.

AB'SABER, Aziz. O paleodeserto de Xique-Xique. Estudos Avançados. São Paulo. 20 (56): 301-8, 2006.

BARRETO, A.M. F. \& SUGUIO K. Considerações sobre a idade e a paleogeografia das paleodunas do médio Rio São Francisco, Bahia. In: Congresso da Associação Brasileira de estudos do Quaternário ABEQUA, IV, São Paulo. Resumos Expandidos, p. 11. 1993.

BARRETO, A. M. F. Interpretação paleoambiental do sitema de dunas fixadas do médio Rio São Francisco, Bahia. Inst. de Geociências, Universidade de São Paulo, São Paulo, Tese de Doutoramento, 174 p. 1996.

BRASIL. Departamento Nacional de Produção Mineral. Projeto Radam. Folha SC. 24 Aracaju: Geomorfologia. Vol. 01. Rio de Janeiro. 1973.

CORREAA, A. C. B. Mapeamento Geomorfológico de detalhe do Maciço da Serra da Baixa Verde - Estudo das relações entre a distribuição dos sistemas geoambientais e a compartimentação geomorfológica. Dissertação Mestrado apresentada ao Programa de Pós-Graduação em Geografia da Universidade Federal de Pernambuco, Recife. 180 p. 1997.

CORRÊA, A. C. B. Dinâmica Gemorfológica dos Compartimentos Elevados do Planalto da Borborema, Nordeste do Brasil. Tese de doutorado apresentada ao Programa de Pós-Graduação em Geografia da Universidade Estadual Paulista, Rio Claro - SP. 2001.

DEMEK, J.. (ed) Manual of detailed geomofphological mapping. Comm Goomorph. Surv. Mapping. IGU, Praga, 368p. 1972.

Departamento de Ciências Atmosféricas - DCA. Dados climatológicos do estado de Pernambuco. Campina Grande. Disponível em: http://www.dca. ufcg.edu.br. Acesso em: 04/11/2010.

FERREIRA, B. Geologia, Geomorfologia e Paleontologia da Margem Pernambucana do Lago de Itaparica, Nordeste do Brasil. Dissertação Mestrado apresentada ao Programa de Pós-Graduação em Geociências da Universidade Federal de Pernambuco, Recife. 187 p. 2010.

FOLK, R. \& WARD, W. Brazos river bar: a study in the significance of grain size parameters. Journal of 
Sedimentary Petrology, 27: 3-26. 1957.

GOUDIE, A. Environmental Change. 2 ed. Oxford, Clarendon. 258 p. 1983.

ERICSON, D.B. \& WOLLIN, G. Pleistocene climates and chronology in deep-sea sediments. Science, 162:1227-1234. 1968.

LIMA, M. I. C. et al. Projeto ferro-titanato de Floresta: minérios de Pernambuco/Radam Brasil. Geologia, [S.l.], v. 1, 314 p., 1985.

MOURA, J. R. da S. Geomorfologia do Quaternário. IN: GUERRA, A. J. T., CUNHA, S. B. Geomorfologia: uma atualização de bases e conceitos. - $5^{\text {a }}$ ed.- Rio de Janeiro: Bertrand Brasil, 472 p. 2003.

PERHPE - Plano Estadual de Recursos Hídricos de Pernambuco. Secretaria de Recursos Hídricos - PE. Recife, 215p. 1998.

POWERS, M.C. A new roundness scale for sedimentary particles. Journal of Sedimentary Petrology, 23:117-119. 1953.

KING, L.. A geomorfologia do Brasil oriental. Revista Brasileira de Geografia. São Paulo. V. 18 (2), p. 147-265. 1956

RODRIGUES, S. C. Análise Empírico-Experimental da Fragilidade do Relevo-Solo no Cristalino do Planalto Paulistano: Sub-bacia do Reservatório Billings. Tese de Doutorado. FFLCH-USP, São Paulo, 267p. 1998.

SHEPARD FP. Nomenclature based on sand- siltclay ratios. Journal of Sedimentary Petrology, 24(3): 151-158. 1954.

SANTOS, E. J. Belém do São Francisco, folha SC. 24-X-A: estados de Pernambuco, Alagoas e Bahia. Brasília CPRM, 84p. (Programa de Levantamentos Geológicos Básicos do Brasil). 1 CD-ROM. 1999.

SANTOS, J. C. O Quaternário do Parque Nacional
Serra da Capivara, Piaui, Brasil: morfoestratigrafia, sedimentologia, geocronologia e paleoambientes. Tese de doutorado apresentada ao Programa de Pós-Graduação em Geociências da Universidade Federal de Pernambuco. 2007.

SILVA, D. G. Evolução Paleoambiental dos Depósitos de Tanques em Fazenda Nova, Município de Brejo da Madre de Deus - Pernambuco. Dissertação de mestrado apresentada ao Programa de Pós-Graduação em Geografia da Universidade Federal de Pernambuco, 155p. 2007.

SUGUIO, K. Rochas Sedimentares. Ed. Edgard Blücher - EDUSP. 500 p. 1980.

SUGUIO, K. (Org.). Quaternário do Brasil. 1. ed. Ribeirão Preto: Holos Editora Ltda, v. 01. 378 p. 2005.

TRICART, J. Exitence de Périodes seches au Quaternaire en Amazonie et dans lês régionas voisines. Revue Geomorphologie Dynamique, 4:145 - 158. 1974.

WILLIAMS, H. E. Notas Geológicas e Econômicas Sobre o Vale do Rio São Francisco. Boletim do Serviço Geológico e Mineralógico, no 12, 56 p. 1925.

Soc. \& Nat., Uberlândia, 25 (2): 363-378, mai/ago/2013 